\title{
PERCEPC̣̃̃O DE PROFESSORES DO ENSINO BÁSICO EM RELAC̣ÃO AS SUAAS PRÁTICAS EDUCATIVAS SOBRE LEISHMANIOSES: UM ESTUDO EM ÁREA ENDÊMICA DE MINAS GERAIS
}

\begin{abstract}
RESUMO: As leishmanioses têm alta prevalência no Brasil e, particularmente, em Divinópolis, Minas Gerais. O desconhecimento das enfermidades favorece sua disseminação. Por isso, este artigo apresenta uma investigação sobre a percepção de práticas educativas realizadas por professores de Ciências e Biologia do ensino básico quanto ao tema leishmaniose. Foram entrevistados dez docentes, e empregou-se o critério de saturação e a análise de conteúdo. Os resultados demonstraram que os professores atribuem pouca importância às leishmanioses, abordam o conteúdo junto aos alunos superficialmente por considerarem-se despreparados. Apontaram, na região, várias situações de risco para as enfermidades e a inexistência de políticas públicas para preveni-las. $\mathrm{O}$ contexto da educação em saúde nas escolas dificulta a adoção de ações profiláticas. São discutidas alternativas para trabalhar o tema nas escolas, integrando ensino de ciências e saúde.
\end{abstract}

Palavras-chave: Leishmanioses. Percepção. Educação em saúde. Professores de Ciências e Biologia.

\section{THE PERCEPTION OF PRIMARY AND SECONDARY SCHOOL TEACHERS REGARDING THEIR EDUCATIONAL PRACTICES ON LEISHMANIASIS: A STUDY IN AN ENDEMIC AREA OF MINAS GERAIS}

ABSTRACT: Leishmaniasis has high prevalence in Brazil and in Divinópolis, Minas Gerais. The lack of knowledge about these diseases favors their dissemination. The perception regarding the educational practices on Leishmaniasis among primary and secondary science and biology teachers was investigated. Ten professionals were interviewed using the saturation criteria and the analysis of content. The results showed that teachers give little importance to Leishmaniasis, address the subject superficially and find themselves unprepared to teach it. They indicated several risk situations in the region and a lack of prophylactic public policies. The context of health education within the educational system complicates the adoption of prophylactic actions. Alternatives to work on Leishmaniasis in schools are discussed, integrating the teaching of science and health.

Keywords: Leishmaniasis, perception, health education, science and biology teachers.

\author{
Viviane Helena de França* \\ Carina Margonari** \\ Virgínia Torres Schall **
}

*Doutoranda e mestre em Ciências
da Saúde, área Saúde Coletiva,
pelo Centro de Pesquisas René
Rachou (CPqRR), Fundação
Oswaldo Cruz (FIOCRUZ Minas).
E-mail: vivianehfranca@cpqrr.fiocruz.br
**Pós-doutorado e doutorado em
Biologia Parasitária pelo CPqRR -
FIOCRUZ Minas. Pesquisadora do
Laboratório de Educação em Saúde e
Ambiente (LAESA- CPqRR).
E-mail: margonari@cpqrr.fiocruz.br
***Doutora em Educação pela
Pontifícia Universidade Católica do
Rio de Janeiro (PUCRJ). Pesquisadora
titular, chefe e fundadora do
Laboratório de Educação em Saúde
e Ambiente do Centro de Pesquisas
René Rachou LAESA -CPqRR.
E-mail: vtschall@cpqrr.fiocruz.br
APOIO: FAPEMIG e CNPq. 


\section{INTRODUC̣ÃO}

As leishmanioses integram um grupo de doenças enzoóticas e zoonóticas causadas por protozoários do gênero Leishmania sp., que se manifestam nas formas clínicas: Leishmaniose Tegumentar Americana (LTA) e Leishmaniose Visceral (LV). Essas podem incapacitar os portadores para o trabalho e para as atividades da vida diária, ocasionando-lhes a exclusão social e, em alguns casos, a morte.

O Brasil está entre os dez países nos quais ocorrem 90\% dos casos mundiais das doenças (ORGANIZAÇÃO MUNDIAL DE SAÚDE - OMS, 2012). Em 2010 foram 26.173 notificações pelas leishmanioses no país, sendo a LTA notificada em todos os estados e a LV em 23 deles (BRASIL, 2012). As medidas de prevenção e controle adotadas pelos serviços de saúde no Brasil privilegiam o controle do vetor, de reservatórios e o tratamento de doentes e dão pouco enfoque à educação em saúde. ((BORGES et al., 2008; LUZ et al., 2009). Luz, Schall e Rabello (2005) observaram que profissionais de saúde e educação desconhecem sobre a LV; e FRANÇA, MARGONARI e SCHALL (2010), afirmam que professores de Ciências e Biologia apresentam concepções incorretas sobre a LTA e a LV.

As ações de prevenção e controle das doenças endêmicas devem ser desenvolvidas como estratégias de controle integrado, associando manejo ambiental, diagnóstico e tratamento precoce com práticas educativas. A educação em saúde no Brasil ainda recebe poucos incentivos e recursos para mobilização de ações preventivas individuais e coletivas (SCHALL, 1998).

A escola é um espaço importante para promover a saúde, a prevenção de doenças, as ações de proteção e o exercício da autonomia e da cidadania. É uma aliada no fortalecimento das capacidades dos indivíduos para a tomada de decisões favoráveis à saúde (MINISTÉRIO DA SAÚDE - MS, 2002). As questões de saúde trabalhadas na escola possibilitam reflexões socioeconômicas, políticas e ideológicas contextualizadas, valorizando o momento histórico dos sujeitos. Pode-se, assim, favorecer a conscientização, a promoção do direito à saúde e a instrumentalização para a ação individual e coletiva (BRASIL, 1998).

Pesquisas de educação em saúde sobre as leishmanioses em escolas de ensino básico demonstraram que professores e alunos podem ser agentes multiplicadores de ações profiláticas na comunidade (UCHÔA et al.,2004; MAGALHÂES et al., 2009). Nas aulas de Ciências e Biologia, podem ser abordadas a LTA e LV de modo contextualizado.

Schall (2010b) destaca que a escola é um espaço potencial para trabalhar o tema saúde e participação social na vida cotidiana, e para refletir sobre ciência e sociedade de forma integrada ao ensino de Ciências. Entretanto, França, Margonari e Schall (2011), em análise de livros didáticos dessas disciplinas sobre o conteúdo das leishmanioses, verificaram que estes contêm informações errôneas e incompletas, desfavorecendo a divulgação de conhecimentos e a reflexão crítica sobre as doenças.

O estudo da situação da educação em saúde sobre a LTA e LV nas escolas de ensino básico do país pode favorecer seu enfrentamento, pois pesquisas e 
iniciativas em relação às leishmanioses direcionadas aos professores e estudantes são imprescindíveis para a conscientização dos brasileiros sobre as enfermidades.

Com o objetivo de contribuir para estratégias de divulgação sobre as doenças e fomentar seu enfrentamento no município de Divinópolis, Minas Gerais (MG), foi realizada a investigação de conhecimentos e opiniões sobre as leishmanioses de professores do Ensino Fundamental e Médio, analisando seu discurso sobre as práticas pedagógicas adotadas junto aos alunos na abordagem do tema.

\section{MÉTODO}

O estudo foi realizado em Divinópolis, MG, área endêmica das leishmanioses. A cidade se localiza próxima aos municípios de Itaúna e Belo Horizonte, nos quais a enfermidade é problema de saúde pública. Recentemente, Margonari et al. (2010) e Maia et al. (2010) verificaram, dentro do perímetro urbano da cidade, alta taxa de flebotomíneos e cães infectados por Leishmania sp. A epizootia já precedeu a epidemia de casos humanos das leishmanioses em várias regiões geográficas (OLIVEIRA et al., 2001). Esse cenário configura uma situação de risco para a expansão da enfermidade na região, pois a população de Divinópolis desconhece práticas preventivas relacionadas às doenças (OLIVEIRA et al., 2009).

Foram selecionados professores de Ciências e Biologia de escolas de ensino básico de Divinópolis, respectivamente das séries finais do Ensino Fundamental $\left(6^{\circ}\right.$ ao $9^{\circ}$ ano) e do Ensino Médio; a partir do levantamento das escolas públicas (13 municipais e 19 estaduais) e privadas (9) no município, e dos professores de Ciências e Biologia (139) que lecionavam nelas. A seleção desses profissionais aconteceu por meio de sorteios aleatórios de 11 professores de Ciências e Biologia, abrangendo todas as redes de ensino. Para o estudo, foram entrevistados 10 professores, atingindo-se o critério de saturação (MINAYO, 2004). Para inclusão dos professores na pesquisa, considerou-se necessário que lecionassem uma das disciplinas e concordassem em participar do estudo, autorizando a gravação das entrevistas.

$\mathrm{Na}$ realização das entrevistas foi utilizado um roteiro semiestruturado, testado e validado previamente, abordando: os dados sociodemográficos e a capacitação profissional dos professores; a situação atual das leishmanioses no município; os conhecimentos e opiniões sobre as doenças; as práticas docentes e os recursos empregados ao abordar tal conteúdo junto aos alunos; as possíveis ações educativas para o enfrentamento das doenças; a compreensão e a prática da educação em saúde.

A duração de cada entrevista variou entre 40 minutos a 1 hora e 30 minutos, sendo realizadas individualmente nas escolas e gravadas em áudio; as informações importantes foram anotadas no diário de campo. As gravações foram transcritas e informatizadas. Após a transcrição, foi realizada a leitura exaustiva das entrevistas e identificadas as falas dos professores relacionadas aos conhecimentos e opiniões sobre a LTA e LV e as situações inerentes ao contexto da educação em 
saúde nas escolas sobre as doenças, sendo estas categorizadas e submetidas à análise de conteúdo (BARDIN, 1977).

O projeto foi aprovado por comitê de ética sob o número de protocolo 15/2009 - CAEE: 0016.0.245.000-09. As entrevistas aconteceram mediante a explicação da pesquisa e a solicitação da assinatura do termo de consentimento livre e esclarecido, sendo empregados nomes fictícios aos entrevistados nas análises e na descrição dos resultados: nomes de pessoas iniciando com $\mathrm{C}$ para professores de Ciências; B, de Biologia; e A, de ambas as disciplinas.

\section{RESULTADOS E DISCUSSÃO}

\section{Características dos professores}

Os dez professores entrevistados têm idades que variam entre 28 e 58 anos. Seis são do sexo masculino e 4 do sexo feminino. Um leciona aulas de Biologia; um, de Ciências e os outros 8 lecionam ambas as disciplinas. Quatro docentes trabalham em escolas estaduais, 3 em estaduais e municipais, 2 em estaduais e privadas, e um apenas em escola privada. O tempo de profissão dos professores variou entre 5 e 20 anos: seis entre 5 e 10 anos; dois, 11 e 15 anos; dois, 16 e 20 anos. Todos possuem $3^{\circ}$ grau completo: Ciências Biológicas (5), Biologia (3), Zootecnia (1), Psicologia (1); este último possui licenciatura plena complementar em Biologia. Um professor tem mestrado, seis possuem especialização e um encontra-se cursando essa última pós-graduação. A renda familiar dos docentes variou de 2,9 a 13,7 salários mínimos e a renda per capita entre 0,7 e 4,7 salários mínimos.

\section{Apresentação e interpretação das categorias}

Todas as falas dos entrevistados foram analisadas e organizadas em categorias. Após leitura do conjunto das entrevistas, foram identificadas 14 categorias e 33 subcategorias que direcionaram a especificação dos temas. A definição operacional levou em conta se a resposta fornecida pelos docentes quanto a um conteúdo pertencia a apenas uma ideia ou se a mais de uma. Foi encontrado um número variável de falas por categoria. Algumas categorias apresentaram um número de comunicações correspondentes ao número de sujeitos entrevistados (10). Outras categorias apresentaram um número de comunicações inferior ou superior aos sujeitos quando foram encontradas mais de uma ou nenhuma ideia de um sujeito por categoria.

No tratamento dos resultados as categorias e subcategorias foram organizadas em seis grandes eixos temáticos: (1) Fontes de informação dos professores sobre as leishmanioses; (2) Compreensão do ciclo biológico das doenças e de terminologias a ele associadas; (3) Terminologia, sintomas e tratamento das enfermidades em seres humanos e animais; (4) Medidas de prevenção e controle das leishmanioses; (5) Abordagem do conteúdo das leishmanioses em sala de aula; (6) Grau de importância atribuído às doenças e denúncia da situação local. 
A seguir serão apresentados os resultados e discussão referentes aos dois últimos eixos temáticos, sobre o processo pedagógico vivenciado por docentes e sua prática no ambiente escolar ao abordarem as leishmanioses. Os quatro primeiros eixos em relação ao conhecimento científico dos professores sobre as doenças foram apresentados em outra publicação (FRANÇA, MARGONARI e SCHALL, 2010).

\section{A) Abordagem do conteúdo das leishmanioses em sala de aula}

Nesse eixo temático encontram-se as ideias dos professores referentes a: autoavaliação do saber sobre as leishmanioses e preparo pedagógico para ensiná-las; abordagem do conteúdo em sala de aula; importância, utilização e adequação dos livros didáticos para ensinar o conteúdo; método de escolha desses materiais e importância do Programa Nacional do Livro Didático (PNLD) nesse processo e na melhora de sua qualidade; compreensão, prática e dificuldades na educação em saúde de estudantes.

\section{Como e quando os professores abordam as leishmanioses}

Os professores se autoavaliaram em relação ao saber sobre as doenças e o preparo pedagógico para educar os alunos sobre a temática. Sete afirmaram saber pouco sobre as leishmanioses ou que se esqueceram do conteúdo, apresentando, em alguns momentos, insegurança e medo ao serem entrevistados a respeito do assunto.

"Agora eu não tenho muita informação sobre ela, assim, não! Eu não chego na sala hoje e vou falar da
leishmaniose igual eu chego e falo da AIDS, que eu tenho certeza! Porque eu não tenho muito conbecimento!
Assim, o conhecimento que eu tenho da leishmaniose em si, é muito, muito básico mesmo!" (Alisson, 34 anos)

Nove professores trabalham o tema em sala de aula: seis ao abordarem protozoários, reino protista; um parasitoses, um doenças de modo geral e outro bactérias e vírus; este último professor até o momento da entrevista não havia lecionado o conteúdo no corrente ano. Um docente disse não trabalhar o tema com os alunos.

"É tratado igual a gente fala com os alunos... no $6^{\circ}$ ano, na $5^{a}$ série a gente começa a falar com eles, então se a gente fala dos protozoários a gente já comenta com eles algumas das doenças mais comuns causadas por protozoários..." (Afrânio, 28 anos).

Cinco professores, como o acima, relataram que trabalham o tema de forma bastante superficial, sem aprofundar no conhecimento sobre as doenças.

"A gente, igual eu te disse, dá uma ênfase maior para a AIDS, para a dengue... A leishmaniose nunca foi um foco, assim, da gente estar trabalhando, né? Com aquela preocupação maior... A gente não recebeu essa orientação para estar passando!" (Alisson, 34 anos).

Para cinco professores essa abordagem superficial das leishmanioses em sala de aula é resultante do grande número de conteúdos que devem ser lecionados 
para cumprir o programa curricular de cada série. Os docentes sentem-se apertados em tempo para lecionar todos os conteúdos, dando, assim, pouca atenção ao tema.

"E se toda doença, a gente for trabalhar tudinho minuciosamente, a gente vai trabalhar só com as doenças no conteúdo de Ciências! Aí não dá, não dá tempo de você ficar tempo demais!" (Alice, 41 anos).

Em síntese, a maioria dos entrevistados informa não abordar ou ter pouco conhecimento para incluir o tema no ensino de Ciências.

\section{Recursos pedagógicos para abordagem das leishmanioses}

Todos os professores abordam o assunto utilizando o livro didático como apoio das aulas para os alunos. Cinco relataram que, embora a internet seja, talvez, o recurso mais utilizado por professores e alunos, os livros didáticos de Ciências e Biologia ainda são subsídios importantes para os estudantes realizarem atividades. Sempre que é cobrado dos alunos utilizarem o livro didático, isso ocorre em sala de aula. Um professor destacou que os livros didáticos são priorizados como recursos educativos em sala de aula porque são fornecidos gratuitamente aos alunos, sendo o material mais acessível a educadores e educandos da rede pública. Para cinco docentes o livro didático é, portanto, o ponto de referência para serem abordadas a LTA e a LV com os alunos.

"No Ensino Fundamental a gente lê dentro da sala de aula. No ensino... na rede pública, os meninos usam mesmo é o livro!" (Andréia, 32 anos).

Três professores, além do livro didático, utilizam outros recursos para trabalhar o conteúdo: pesquisa (2); produção de jornal (1).

Embora um professor tenha se posicionado como desfavorável à adoção de livros didáticos pelas escolas, e favorável a que eles fossem elaborados pelo próprio educador, disse segui-los ao abordar o tema em sala de aula. Esse docente confundiu as características das leishmanioses com a esquistossomose, indicando a necessidade de disponibilizar, nas escolas, bibliografias de qualidade e cientificamente corretas.

Três entrevistados relataram que o conteúdo das leishmanioses não se encontra presente de maneira satisfatória nos livros didáticos de Ciências e Biologia. Sete professores afirmaram que o conteúdo é disponibilizado em tais materiais de forma muito resumida, com poucas informações. A carência dessas informações nos livros didáticos é percebida pelos professores como obstáculo para abordagem do conteúdo em sala de aula.

"É, o meu livro didático de Biologia tem um quadrinho, pequenininho, que deve ter umas 4 ou 5 linhas, da leishmaniose. É muito pouco! Não tem informação! Os livros de Ensino Fundamental não trazem nada... Só fala assim: 'A Leishmaniose, a Leishmania... Não fala mais nada, e fala do Birigui... e não coloca nada cientifico, e coloca também a prevenção... é, combater os mosquitos! Só isso! Não coloca mais nada!" (Ana, 58 anos). 
Mesmo os livros didáticos de Ciências e Biologia sendo percebidos como "incompletos" e "insuficientes" em relação à LTA e à LV por sete professores, observou-se sua confiança nas informações que esses materiais apresentam. Para seis professores os livros didáticos apresentam conceitos cientificamente corretos, levando-os a adotá-los e segui-los apesar das falhas apontadas por França, Margonari e Schall (2011) e outros autores que analisam temas de saúde nesses recursos, como Mohr (2000), Schall (2010a), Batista, Cunha e Cândido (2010).

"Ai é que é... porque igual nós estamos conversando, eu tenho que confiar no meu material didático... Se eu for ensinar para o menino, se o menino vai ler o livro, pesquisar no livro e responder as questões do livro, eu tenho que julgar que aquelas informações sejam corretas! Eu não posso nem duvidar dela, porque senão eu nem trabalho! O livro didático é incompleto, mas eu acho que, assim, em termos de correto... até agora os livros que eu tenho adotado, eu acredito que sejam corretos!" (Ana, 58 anos).

França, Margonari e Schall (2011) verificaram em estudo de análise de 16 livros didáticos de Ciências e Biologia, avaliados e indicados pelo Programa Nacional do Livro Didático (PNLD-2008) e pelo Programa Nacional do Livro do Ensino Médio (PNLEM-2009) e adotados em escolas públicas de 2008 a 2011, que o conteúdo das leishmanioses em tais materiais é falho. Foram encontrados, nos livros de Ciências e Biologia, respectivamente, 64,3\% e 53,3 \% de lacunas nas informações e $25,7 \%$ e $32,2 \%$ de erros conceituais. Ressalta-se a importância dos textos de tais materiais apresentarem conteúdos corretos cientificamente, promovendo a construção de conhecimentos úteis ao enfrentamento das enfermidades. Sete docentes consideraram importante os livros didáticos abordarem o conteúdo das leishmanioses fornecendo informações mais detalhadas.

"É os livros são falhos nesse aspecto, eles poderiam ser melhorados, e traz̧er mais informação! Com certez̧a (o assunto) deveria ser abordado nos livros didáticos para que nós possamos ficar mais atentos a esse vetor, a essa doença que circula no meio de nós, né?" (Augusto, 40 anos).

Cinco entrevistados destacaram, ainda, que os livros didáticos adotados nas escolas são inadequados em relação aos conteúdos curriculares cobrados de professores e alunos. Para esses profissionais, tais materiais não apresentam os conteúdos a serem lecionados por série na mesma sequência do programa curricular da Secretaria de Educação do Estado de Minas Gerais, ou seja, do CBC - os Conteúdos Básicos Comuns por disciplina e série. É exigido dos professores lecionarem determinados conteúdos em cada série que não se encontram disponibilizados nos respectivos livros didáticos de Ciências e Biologia. Esse fato culmina com professores encontrando dificuldades para ministrar suas aulas, e alunos com a formação comprometida em determinados temas, pois o livro didático é, ainda, em algumas escolas, o único material didático disponível. 
"A gente trabalha mais com o CBC... Agora no Ensino Fundamental houve uma diversificação.... Então, às vezes a gente tem que usar o livro lá da outra série, porque o conteúdo do $C B C$ não está de acordo com o livro didático! Então, às vezese é um tema que épara ser trabalhado no $5^{\circ}$ ano, e agora você vai encontrar lá no livro do $6^{\circ}$ e do $7^{\circ}$... No livro do Ensino Médio tem matéria do $1^{\circ}$ ano que eu vou encontrar lá no livro do $3^{\circ}$ ano, tem matéria do $3^{\circ}$ que está no livro do $1^{\circ}$. Antes a gente utilizava, por exemplo, o livro do $1^{\circ}$ ano e programava na ordem daquele livro..." (Alisson, 34 anos).

Os professores ressaltaram que a escolha de livros didáticos nas escolas ocorre por meio de reuniões e discussões entre os docentes de cada área. Nas escolas públicas são separadas três opções de livros considerados bons para serem adotados nas escolas, e dentre estes, as Secretarias de Educação enviam um. Na rede privada os docentes, junto à coordenação e direção da escola, escolhem o livro a ser adotado. Os entrevistados analisam os livros atentando para sua qualidade: se são dinâmicos, apresentam ilustrações atraentes; se têm bons e diversificados exercícios, linguagem adequada e contextualizada à realidade dos alunos; se o manual do professor e o livro de alunos apresentam os conteúdos de forma interessante e coerente com o programa curricular.

Um professor destaca que por ser contratado na rede pública estadual, quando começa a lecionar em determinada escola, os livros já foram escolhidos. Para esse entrevistado, os livros didáticos que são escolhidos e adotados na escola em que atua são sempre os mesmos dos anos anteriores.

Para cinco professores, mesmo acontecendo a escolha dos livros didáticos nas escolas da rede pública, essa não se concretiza como eles gostariam. Embora em várias ocasiões tenham sido escolhidas três opções de livros didáticos $\left(1^{\mathrm{a}}, 2^{\mathrm{a}}\right.$ e $3^{\text {a }}$ ) por área, para serem adotados nas escolas, o livro enviado pela Secretaria de Educação não havia sido a $1^{\mathrm{a}}$, a $2^{\mathrm{a}}$, nem a $3^{\mathrm{a}}$ opção.

"Olha, nós escolhemos um livro para o ano que vem. O que eu escolbi não vai poder vir, porque a gente escolheu e quando jogou no programa esse não aceitou... O programa da superintendência, da secretaria... Ai, o que en tive que fazer: voltar e escolher um outro livro que não fosse pior, sabe como?" (Ana, 58 anos).

Observou-se também certa desconexão entre o PNLD e o PNLEM, a escolha de livros didáticos por professores e o que eles acham a respeito da contribuição desses programas para a qualidade de tais materiais. Questionados sobre a importância e a contribuição do PNLD e do PNLEM na escolha dos livros didáticos e se houve melhoria em sua qualidade, um docente demonstrou não saber o que eram tais programas. Dois já haviam ouvido falar, sem os conhecer em detalhes, e não percebiam melhora na qualidade dos livros didáticos. Apenas três professores conheciam o PNLD e o PNLEM, mas não relataram melhora em tais materiais nos últimos anos. Somente um docente descreveu que, além de conhecer tais programas, tem ocorrido um aprimoramento na qualidade dos livros didáticos nos anos recentes. Nenhum professor costuma receber os catálogos e informações sobre o PNLD e o PNLEM durante a escolha dos livros didáticos nas escolas. 
"Eu não vejo, assim, melhora na qualidade, não! Por mais que a gente traga outras coisas, o que a gente tem de apoio ali mesmo, o que tem de suporte para trabalhar com o aluno, muitas das vezes acaba sendo o livro didático... A gente não tem material disponivel!"(Alisson, 34 anos).

As escolas nas quais os professores lecionam, com exceção de uma, fazem uso dos livros didáticos indicados pelo PNLD-2008 e pelo PNLEM-2009. Entretanto, oito dos onze títulos de livros de Ciências e Biologia citados pelos docentes como utilizados nessas escolas possuem informações errôneas e incompletas em relação às leishmanioses, de acordo com França, Margonari e Schall (2011). Duas escolas utilizavam livros didáticos de Ciências indicados pelo PNLD-2008 que não apresentavam informações sobre a LTA e a LV. Uma escola fazia uso de um livro de Biologia não indicado pelo PNLEM- 2009.

Verifica-se, assim, que o livro didático é o recurso mais empregado em sala de aula pelos docentes para lecionarem o conteúdo, apesar de apresentarem informações insuficientes. Segundo os professores, esses materiais precisam ser melhorados para o enriquecimento do conteúdo, assim como respeitada sua escolha do livro didático a ser adotado na escola para que este seja contextualizado com a realidade dos alunos. Essas são questões cruciais que merecem atenção para se valorizar os conhecimentos e habilidades construídas em sala de aula por professores e alunos, potencializar a educação em saúde vivenciada nas disciplinas de Ciências e Biologia para que sejam adotadas ações profiláticas em nível comunitário em relação às leishmanioses.

\section{Como os professores percebem a educação em saúde}

Os entrevistados apresentaram comentários sobre o que compreendem, e como praticam a educação em saúde em sala de aula e na escola. Essa é vista por três docentes como um conhecimento e informação que visa à prevenção de doenças; outro professor a considera um conhecimento que impacta na qualidade de vida; três a enxergam como informações que visam melhorar a saúde dos sujeitos. Dois docentes descreveram-na como uma conscientização que capacita os sujeitos para terem saúde.

Questionados se praticam a educação em saúde em sala de aula, nove professores disseram que sim e um afirmou não praticar, ou quando isso ocorre é somente com o tema educação sexual, a pedido da direção da escola.

A abordagem da educação em saúde pelos docentes junto aos alunos variou: 5 citaram que a trabalham junto aos conteúdos curriculares por meio de pesquisas, produção de jornais, cartazes, charges, uso de reportagens, filmes e vídeos; 4 citaram que a abordam de forma interdisciplinar por meio do trabalho de campo, palestras, projetos nas escolas e atividades associadas à questão da saúde; apenas 1 professor trabalha a educação em saúde de maneira informal, por meio do diálogo e do aconselhamento aos alunos.

Três professores citaram que os alunos têm acesso a muitas informações, entretanto, não sabem como apropriar-se delas em benefício à própria qualidade 
de vida. Para esses docentes, o impasse ao se trabalhar a educação em saúde consiste em fazer com que os estudantes coloquem em prática os ensinamentos.

Sete professores apontaram as principais dificuldades para se praticar a educação em saúde na escola: ausência de material didático (4); ausência de laboratórios de Ciências e Biologia e de informática (4) ausência de biblioteca e sala de vídeo (2); falta de tempo para os professores planejarem as aulas e projetos interdisciplinares (4); salas de aula com número excessivo de alunos (2); inexistência de capacitação dos professores (2); ausência de intercâmbio da escola com outros setores como o da saúde e de apoio das secretarias de educação (2); inexistência de participação dos alunos e família no processo educativo (2).

'É... falta material didático adequado, um laboratório, visitas articuladas já ao nosso programa... Se eu quiser eu tenho que correr atrás... Eu fiz. um (curso) também na UFMG que eu corri atrás... Quando eu falo correr atrás, é correr atrás assim: você vai, pesquisa, vê aonde que tem o curso, você quer, você paga, você investe... você não ganha! Você mata aula, e, se tem suas aulas, não é dispensado! Você perde a carga horária, perde o rendimento, aí você tem que faz̧er isso se quiser... senão... [...] Agora fechou o nosso laboratório aqui... não tem nem como você levar aluno para lá... Eu não tenho uma lupa, um microscópio! Eu não tenho nada em mãos! Então, uma aula prática para eles faz falta demais... porque Biologia é tudo abstrato!" (Ana, 58 anos).

"É um caos total na educação, você vive por improvisar! Deveria ter um documentário sobre leishmaniose, dengue, que chegasse... Existe, mas não chega na escola e nem adianta chegar sem ter um espaço adequado! Para ter uma noção, não existe uma sala, eu não estou falando dessa escola, são todas! Eu já passei por muitas! Então, o maior problema é a carência e a dificuldade que a escola pública enfrenta a nivel estrutural, e a nivel do meu aluno, o seu desinteresse em relação a isso... Esse desinteresse se torna mais forte quando os instrumentos que eu tenho são uns instrumentos, é, dos anos 40 ! O século XXI ainda não chegou na sala de aula em termos de tecnologia!" (Augusto, 40 anos).

Silva e Helal (2010) descrevem que o ensino de Ciências, principalmente no Ensino Fundamental (pontuamos que no Ensino Médio também) deve contar com projetos que congreguem diversos saberes, que abordem a complexidade do mundo, a experiência vivida pela pesquisa e a construção colaborativa de conhecimentos. Contudo, destaca-se, neste estudo, que o cenário das escolas de educação básica, conforme relataram os professores, é deficitário para se trabalhar a educação em saúde, a prevenção de doenças e a promoção de qualidade de vida com estratégias diferenciadas, interessantes e contextualizadas na realidade dos alunos, pois os docentes não têm disponíveis, nesses espaços, infraestrutura, recursos e apoio.

\section{Parcerias para 0 ensino com universidades, secretarias e serviços de saúde}

Em relação a parcerias entre a escola e o setor saúde, nove docentes disseram que essas inexistem. Apenas um professor citou o "PEAS", um projeto da Secretaria Estadual de Educação, em uma escola, que trabalha a afetividade e a sexualidade entre jovens. Nove professores ressaltaram que não existem projetos e trabalhos contínuos de intercâmbio entre as escolas e os serviços de saúde, embora essas parcerias sejam percebidas como interessantes e importantes para uma educação em saúde de qualidade nas escolas. 
"Não, aqui não! Eu estou aqui vai fazer... e nunca vi uma pessoa vir se apresentar (profissional de saúde)... Muitas pessoas do bairro não sabem nem a qual região pertence para fazer um tratamento de saúde... Aqui, se o professor quiser, é cada um por sil" (Antônio, 28 anos).

Apenas dois professores comentaram sobre a existência de parcerias entre escolas e universidades e faculdades. Um docente descreveu sobre uma reunião entre essas instituições, mas as parcerias não se concretizaram. Outro relatou que há, em alguns momentos, projetos de extensão entre a escola, faculdades e cursos técnicos da área de saúde. Para um professor, há muita dificuldade para se conseguir um palestrante e ter apoio na própria escola. Os docentes desconhecem programas ou políticas públicas de educação em saúde sendo colocadas em prática no contexto escolar.

"Então, às vezes, assim, tem um projeto que dá certo né? Aí pega aquele projeto e mostra como se fosse uma realidade global... e não é! Eu não vi isso em Divinópolis ainda... [...] Que eu veja, assim, na realidade do dia a dia, não!” (Augusto, 40 anos).

Diante das dificuldades enfrentadas e da inexistência de parcerias para trabalhar a educação em saúde na escola, os professores sugeriram alternativas para melhorar esse cenário: parcerias entre o setor de saúde e educação (6); capacitação dos docentes e incentivos pela Secretaria de Educação (2); disponibilização de materiais audiovisuais e laboratórios (5); aprimoramento da qualidade dos livros didáticos (5); parcerias com a família (1); expansão da carga horária do aluno na escola (1); aumento dos salários dos professores para que esses tenham uma menor carga horária de aulas e, assim, possam dispor de mais tempo para planejamento e realização de projetos (1).

\footnotetext{
"Eu sugiro que... os livros sejam mais aprimorados com melhor qualidade de informação, mais dinâmicos, atrativos e com diversificaşão de imagens, de gráficos, que tragam junto um material visual, audiovisual... $e$ que para cada capitulo tenha um material que você possa imprimir e trabalhar com exercícios, porque eu que tenho que correr atrás, porque são poucos os exercícios nos livros ... E que a escola integrasse no século XXI em termos de mídia, texto... Para que se possa trabalhar a nivel do contexto bistórico que estamos de informaşão..." (Augusto, 40 anos).
}

Dois entrevistados comentaram que é importante trabalhar a educação em saúde no contexto escolar. Para eles, a escola é o principal espaço para divulgar informações sobre a saúde e para construir atitudes saudáveis.

"Porque é dentro da escola que o aluno consegue aprender muita coisa relacionada a isso, e ele pode colocar isso em prática realizando alguma atividade em casa, ou até mesmo passando esse conhecimento... Então, é importante que seja o começo dessa disseminação da informação correta né? .... começo tem que ser aqui, né?!" (Afrânio, 28 anos). 
A situação atual das escolas de ensino básico revela questões cruciais que refletem a precariedade da educação em geral, do ensino de Ciências e da educação em saúde. Inexistem processos de formação e capacitação dos docentes. Seu pouco preparo pedagógico com relação a alguns temas de saúde, especificamente sobre a LTA e a LV, endêmicas na região do estudo, a ausência de políticas públicas e dispositivos locais nesse sentido, assim como recursos de informação, incentivos e apoio pelas secretarias de educação, direção das escolas e do setor de saúde contribuem para que as leishmanioses ainda sejam percebidas como enfermidades distantes da realidade de professores e alunos, e para que não sejam prevenidas na escola e na comunidade.

Segundo o Ministério da Educação (MEC) e o MS Brasil (2007), o Programa Saúde na Escola visa articular a parceria entre as escolas e os serviços de atenção básica. Entretanto, essas ações não são implementadas devido à carência de recursos financeiros, materiais e humanos, conforme apontam as falas dos professores. É importante fomentar parcerias entre os professores e os profissionais de saúde nas escolas de ensino básico para haver a divulgação de conhecimentos e a construção de conceitos sobre o tema saúde, a produção de consciência crítica e o empoderamento de estudantes em relação ao processo saúde-doença e enfrentamento das leishmanioses.

\section{B) Grau de importância atribuído às doenças e a denúncia da situação local}

Nesse eixo temático, encontram-se as falas dos professores a respeito da sua avaliação sobre a importância das leishmanioses; a percepção do conhecimento da população de Divinópolis sobre a LTA e a LV; a percepção da situação dessas doenças no município e de políticas públicas relacionadas ao tema; a mobilização para ações a partir da pesquisa.

Para cinco professores entrevistados, as leishmanioses são doenças de pouca importância: três as citaram como um assunto que ninguém se importa, que é esquecido; e dois como algo que não é popular, que não é comum.

"Uma novidade... eu vejo que é uma novidade, é como se não existisse mesmo... [... ]Não é uma doença muito comum, assim, não... popular..." (Afrânio, 28 anos).

Para dois docentes a "leishmaniose" é uma doença pouco divulgada. Apenas um professor considera a doença importante e complicada. Na percepção dos dez professores, a população de Divinópolis também desconhece sobre as leishmanioses: não sabe o que são a LTA e a LV, nem como preveni-las.

"Eu acho que o pessoal não tem nem conhecimento, a maioria... Eu acho que uns $80 \%$ não tem nem conhecimento!"(Carmem, 29 anos).

"Eu posso chegar para uma sala agora de 40 alunos e perguntar um aluno se ele já ouviu falar disso, de $6^{\circ}$ ano, ele vai falar que não... Posso chegar numa sala de 20 professores, uma sala com 20 professores e perguntar se eles sabem do assunto que eles vão falar que não...” (Antônio, 28 anos). 
Oliveira et al. (2009) realizaram pesquisa avaliando o nível de conhecimento da população de Divinópolis sobre as leishmanioses e verificaram que apenas 50\% sabiam o que são a LTA e a LV, $72 \%$ desconheciam a transmissão da doença e $49 \%$ a $69 \%$ afirmaram que o cão é reservatório.

Entretanto, de acordo com a fala de cinco professores, a cidade de Divinópolis apresenta situações que colocam em risco a expansão das doenças. Foram apontadas como situações de risco para as leishmanioses no município: "muitos cães de rua soltos na cidade" (5); a existência de grande número desses animais infectados por Leishmania sp. (2); municípios próximos apresentando casos das doenças (Itaúna, Arcos, Belo Horizonte, Bambuî) (2); grande índice de "pernilongos" na cidade (1), sendo esses identificados como vetores das leishmanioses; muito lixo nas ruas (1); desconhecimento da população sobre as doenças (1).

"Tem um indice de cachorro na rua muito grande... Você chega aqui no centro da cidade, tem muito cachorro! É um cachorro que tem bastante lesão no pêlo... A gente vê um número de cães muito grande e um número de pernilongos muito grande! Imagina se isso vira um surto!’(Bruno, 34 anos).

Um professor afirmou que às vezes ocorrem surtos da enfermidade no município, e dois docentes informaram que alguns bairros apresentam vários casos de cães com leishmanioses. Um desses dois últimos docentes destacou que, além do cão de um irmão, uma clínica veterinária havia diagnosticado vários outros cães infectados na região. Um quarto professor ouviu falar da ocorrência de casos na cidade, embora pessoalmente não conhecesse nenhum.

\footnotetext{
"A minha cunhada falou que lá próximo ao bairro dela, que é no bairro Nações, tinha vários cachorros com a mesma doença... E no PET ${ }^{2}$ que ela levou o cachorro para o veterinário dar uma olhada, ele falou que estava tendo muito na região! E está saindo também em reportagens, em jornais locais, que a leishmaniose está na nossa região e para a gente tomar cuidado... Como é uma doença que as pessoas não conbecem, né? Explicando..."(Afrânio, 28 anos).
}

Maia et al. (2010) analisaram 74 amostras de sangue de cães de seis clínicas veterinárias de Divinópolis em 2009 e verificaram que os exames sorológicos (Elisa e Rifi) apresentaram 36,5\% de positividade para a infecção por Leishmania sp.

Sete professores ressaltaram que apesar disso, não existem políticas públicas direcionadas ao enfrentamento das doenças no município. Para os docentes, não há campanhas e divulgação de informações sobre a LTA e a LV, o que dificulta sua prevenção.

"Eu nunca vi nada voltado para essa doença até hoje! Parece, às vežes, que ela é até um pouco esquecida... A gente até vê falando um pouco... Você vê até animais com a doença... já viu alguma coisa na televisão comentando... Ai, faz uma observação para a população de cuidado... Mas depois, também, nem passa o resultado, se acabou, se continua, como foi tratado... se os animais foram tratados ou foram sacrificados... Assim, passa a questão!"

(Alice, 41 anos). 
Segundo alguns estudos, a população brasileira realmente conta com poucas políticas públicas direcionadas ao enfrentamento da enfermidade. Apesar das ações recomendadas pelo MS, Brasil (2009), serem direcionadas ao diagnóstico da doença, tratamento de casos humanos, vigilância e monitoramento canino, realização de eutanásia de cães sororreagentes, vigilância entomológica, saneamento ambiental, controle químico e educação em saúde, há lacunas na importância e tipo de enfoque atribuído às práticas educativas. De acordo com Luz et al. (2009) e Borges et al. (2008), os programas de controle das leishmanioses no Brasil, conforme comentado, não priorizam a educação em saúde. Estudos de Reis et al. (2006); Oliveira et al. (2009) e de Borges et al. (2008) demonstraram que os brasileiros desconhecem sobre as leishmanioses, não sabem sobre sua transmissão e manifestações e, em alguns casos, confundem a LTA e a LV com dengue e com a Leptospirose, o que evidencia o desconhecimento de medidas preventivas a seu alcance.

Três professores, ao falarem sobre a inexistência de políticas públicas direcionadas às leishmanioses, salientaram novamente a importância de divulgar informações e de conscientizar a população sobre as doenças. Dois desses docentes voltaram a destacar a escola como um espaço propício para tal.

"Então, eu acho que deveria ter uma informação muito grande, uma conscientização muito grande da população, e estar falando desses animais, do risco que eles trazem para a população... E fazer da escola, como nós acabamos de falar, um poço de informação, porque aqui é o melhor lugar para distribuir esses folhetos, essa conscientização e trabalhar em projetos..." (Ana, 58 anos).

Sete professores, diante das entrevistas, manifestaram-se mobilizados para ações nesse sentido. Estes demonstraram curiosidade em saber mais sobre o assunto e em esclarecer algumas dúvidas. Conscientes de seu desconhecimento sobre as doenças, apresentaram interesse em pesquisar e estudar sobre o tema; e alguns demonstraram o desejo de trabalharem o conteúdo com os alunos, dando-lhe maior ênfase.

"Igual eu falei, não é um assunto que é muito popular, pelo menos entre meus alunos, familiares e colegas, muitas pessoas acabam escutando falar e passam informação errada... Vejo também que eu preciso, né?... como é um assunto que hoje ele está aparecendo para a gente... então, a gente tem que dar uma estudada melhor sobre isso... porque vão surgir dúvidas e essas dúvidas vão fazer com que eu busque e vão melhorar meu conbecimento!" (Afrânio, 28 anos).

"Agora, por exemplo, você fazendo isso, está me levando a pesquisar, a pegar mais informação para eu trabalhar com meus meninos sobre a leishmaniose..." (Ana, 58 anos).

\section{CONSIDERACְ̃̃ES FINAIS}

As leishmanioses são doenças negligenciadas pelo poder público e pouco conhecidas pelos professores de ensino básico em Divinópolis. Os dados do MS, 
Brasil (2012), sobre os casos das doenças, demonstram que os programas de controle que vigoram no Brasil não têm conseguido diminuir o número de pessoas acometidas apenas com ações biomédicas e estratégias educativas restritas aos serviços de saúde.

Embora a maioria dos professores entrevistados trabalhe a educação em saúde em sala de aula e lecione o conteúdo das leishmanioses, todos afirmam que nunca passaram por processos de formação abordando a temática e sentem-se inseguros para trabalhar o tema junto aos alunos, pois se consideram pouco preparados para tal (FRANÇA, SOUZA, SCHALL; 2010). Os docentes apontam os livros didáticos de Ciências e Biologia sugeridos pelo PNLD e pelo PNLEM como insuficientes para promoverem o conhecimento sobre as enfermidades, confirmando estudos de França, Souza e Schall (2010) e França, Margonari e Schall (2011), que demonstraram lacunas de informação (e erros conceituais) sobre a LTA e a LV presentes nesses materiais. Tais livros necessitam ser revisados, corrigidos e atualizados para que educadores e educandos possam apropriar-se do conteúdo e divulgar conhecimentos e ações preventivas na comunidade de forma coerente.

Nas escolas inexistem outros recursos pedagógicos além do livro didático para trabalhar o tema com os alunos. Não há, também, programas, políticas e parcerias com o setor saúde para promover uma educação em saúde contextualizada e atualizada. Essas dificuldades para se praticar a educação em saúde nas escolas, sobre as doenças associadas aos vários fatores de risco para a LTA e a LV na região, configuram um cenário favorável a sua disseminação e agravamento no município.

É imprescindível denunciar a pouca importância que ainda é dada à educação em geral e à educação em saúde no Brasil, em Minas Gerais e em Divinópolis. Os relatos dos professores denunciam aspectos cruciais como a não correspondência do livro didático escolhido ao de fato recebido nas escolas, a falta de infraestrutura nas escolas e processos de educação permanente, e sugerem incluir novas tecnologias de informação para serem disponibilizadas junto ao livro didático, alertando sobre o descompasso das inovações do século XXI e o atraso da escola , que parece ainda estar no século XX. Schall (2010b) comenta que as escolas devem ter disponíveis para professores e alunos trabalharem, além do livro didático, outros recursos como livros paradidáticos e literários, materiais lúdicos (jogos, vídeos, fantoches), informativos complementares (vídeos, folhetos, cartazes) e equipamentos para práticas laboratoriais, dentre outros.

Com este estudo, observa-se a necessidade de fomentar processos de formação junto a esses profissionais, pois a educação em saúde contextualizada à realidade local poderá promover a participação dos alunos e da comunidade na construção e na luta por direitos à saúde. É importante serem criadas ações de educação permanente junto aos professores do ensino básico e profissionais de saúde, valorizando seu trabalho conjunto na promoção da educação em saúde nas escolas e no desenvolvimento de projetos interdisciplinares que abordem o processo saúde-doença e a promoção de qualidade de vida, incluindo o tema das leishmanioses e outras doenças negligenciadas, que são endêmicas no Brasil. 


\section{NOTAS}

${ }^{1}$ PEAS Juventude - Programa Educacional de Atenção ao Jovem da Secretaria de Estado de Educação de Minas Gerais

${ }^{2}$ PET-SHOP - Lojas de animais.

\section{REFERÊNCIAS BIBLIOGRÁFICAS}

BARDIN, Laurence. Análise de Conteúdo. Tradução Luís Antero Reto e Augusto Pinheiro. Lisboa: Edições 70, 1977.

BATISTA, Marcus Vinícius Aragão; CUNHA, Marlécio Maknamara Silva; CÂNDIDO, Alexandre Luna. Análise do tema virologia em livros didáticos de biologia do ensino médio. Revista Ensaio Pesquisa em Educação em Ciências, Belo Horizonte, v.12, n.01, p.145-158, jan./abr, 2010.

BORGES, Bárbara Kellen Antunes. et al. Avaliação do nível de conhecimento e atitudes preventivas da população sobre a leishmaniose visceral em Belo Horizonte, Minas Gerais, Brasil. Cadernos de Saúde Pública, Rio de Janeiro, v.24, n.4, p.777-784, abr., 2008.

BRASIL. Ministério da Educação. Ministério da Saúde. Decreto No 6.286, de 5 de dezembro de 2007. Institui o Programa Saúde na Escola -PSE, e dá outras providências. 2007. Disponível em:< http://www.planalto.gov.br/ccivil_03/_ato2007-2010/2007/decreto/d6286.htm >. Acesso em: 10 mar. 2012.

BRASIL. Ministério da Saúde. Secretaria de Vigilância em Saúde. Guia de Vigilância Epidemiológica. $7^{\text {a }}$ ed. Brasília: Ministério da Saúde, 2009.

BRASIL. Ministério da Saúde. Sistema de Informação de Agravos de Notificação- SINAN. Relatórios Gerenciais. 2012. Disponível em: <http://dtr2004.saude.gov.br/sinanweb/> Acesso em: 12 mar. 2012.

BRASIL. Secretaria de Educação Fundamental. Parâmetros curriculares nacionais: saúde. In: Parâmetros Curriculares Nacionais: terceiro e quarto ciclos: apresentação dos temas transversais. Secretaria de Educação Fundamental.Brasília: MEC/SEF, 1998, p.243-283. Disponível em: < http://portal. mec.gov.br/seb/arquivos/pdf/saude.pdf> Acesso em: 10 mar. 2012.

FRANÇA, Viviane Helena; MARGONARI, Carina; SCHALL, Virgínia Torres. Análise de livros didáticos de ciências e biologia e investigação de representações sociais de professores do ensino básico. In: CONGRESSO NACIONAL DE EDUCAÇÃO PARA SAÚDE; CONGRESSO LUSO-BRASILEIRO DE EDUCAÇÃO PARA A SAÚDE, 3.,1., 2010, Covilhã-Portugal. Anais... Covilhã-Portugal: CNES;CNLBES, 2010.

FRANÇA, Viviane Helena; MARGONARI, Carina; SCHALL, Virgínia Torres. Análise do conteúdo das Leishmanioses em livros didáticos de ciências e biologia indicados pelo Programa Nacional de Livros Didáticos (2008/2009). Ciência \& Educaşão, Bauru, SP, v. 17, n. 3, p. 625-644, 2011.

LUZ, Zélia M. Profeta et al. The organization of health services and visceral leishmaniasis: an integrated intervention to improve diagnosis and treatment. Cadernos de Saúde Pública, Rio de Janeiro, v.25, n.5, p.1177-1184, mai, 2009.

LUZ, Zélia Maria Profeta; SCHALL, Virgínia; RABELLO, Ana. Evaluation of a pamphlet on visceral leishmaniasis as a tool for providing disease information to healthcare professionals and laypersons. Cadernos de Saúde Pública, Rio de Janeiro, v.21, n.2, p.606-621, 2005.

MAGALHÃES, Danielle Ferreira et al. Dissemination of information on visceral leishmaniasis from schoolchildren to their families: a sustainable model for controlling the diasease. Cadernos de Saúde Pública, Rio de Janeiro, v.25, n.7, jul., p.1642- 1646, July, 2009.

MAIA, Kamilla et al. Prevalência da Leishmaniose Canina no Município de Divinópolis, MG. In: XLVI CONGRESSO DA SOCIEDADE BRASILEIRA DE MEDICINA TROPICAL, 46., 2010, Foz do Iguaçu. Anais... Foz do Iguaçu: CSBMT, 2010. 
Percepção de professores do Ensino Básico em relação as suas práticas educativas sobre Leishmanioses: um estudo em área endêmica de Minas Gerais

MARGONARI, Carina et al. Phlebotomine Sand Flies (Diptera: Psychodidae) and Leishmania Infection in Gafanhoto Park, Divinópolis, Brazil. Journal of Medical Entomology, [s.l], v. 47, n.6, p.1212-1219, 2010.

MINAYO, Maria Cecília Souza. O desafio do conhecimento: pesquisa qualitativa em saúde. $8^{a}$ ed. São Paulo: Ed. Hucitec, 2004.

MINISTÉRIO DA SAÚDE. Secretaria de Políticas de Saúde. A Promoção da saúde no contexto escolar. Informes Técnicos Institucionais. Revista de Saúde Pública, Florianópolis, v.36, n.2, p. 533-535, 2002.

MOHR, Adriana. Análise do conteúdo de saúde nos livros didáticos. Ciência \& Educaşão, Bauru, v.6, n.2, p.89-106, 2000.

OLIVEIRA, Cláudia Di Lorenzo et al. Spatial distribution of human and canine visceral leishmaniasis in Belo Horizonte, Minas Gerais State, Brasil. 1994-1997. Cadernos de Saúde Pública, Florianópolis, v.17, n.5, p.1231-1239, 2001.

OLIVEIRA, Michael Éder. et al. Avaliação do nível de conhecimento da população e fatores de risco das Leishmanioses no município de Divinópolis, Minas Gerais, Brasil. Revista da Sociedade Brasileira de Medicina Tropical, Recife, v.42, p.268-268, 2009.

ORGANIZAÇÃO MUNDIAL DE SAÚDE (OMS). Temas de Salud-Leishmaniasis. 2012. Disponível em: < http://www.who.int/leishmaniasis/en/> Acesso em: 24 mar. 2012.

REIS, Dener Carlos. et. al. Health education and social representation: an experience with the control of tegumentary leishmaniasis in an endemic area in Minas Gerais, Brazil. Cadernos de Saúde Pública, Rio de Janeiro, v.22, n.11, p.2301-2310, nov., 2006.

SCHALL, Virgínia Torres. An interactive perspective of health education for the tropical disease control: the schistosomiasis caso. Memórias do Instituto Oswaldo Cruz, Rio de Janeiro, vol. 93, suppl. I, p.51-58, out., 1998.

SCHALL, Virgínia Torres. Educação e divulgação científica sobre moluscos de importância médica - Breve análise de materiais informativos sobre esquistossomose. In: ENCONTRO BRASILEIRO DE MALACOLOGIA, 19., 2010. Rio de Janeiro. ECOS DO XIX. Rio de Janeiro: EBM, 2010a. p. 391-403.

SCHALL, Virgínia Torres. Saúde \& Cidadania: entrelaçando textos didáticos, paradidáticos e literários. In: MINISTÉRIO DA EDUCAÇÃO. Secretaria de Educação Básica. Ciências: ensino fundamental. (Coordenação Antônio Carlos Pavão). Coleção Explorando o Ensino, Brasília: MEC, 2010b, p.179-196.

SILVA, Tiago Ribeiro; HELAL, Igor. O ensino de ciências e a alfabetização: da homogeneização ao trabalho com projetos. Ciência em Tela, Rio de Janeiro, v.3, n.2, p.1-8, 2010.

UCHOA, Cláudia Maria Antunes. et al. Educação em saúde: ensinando sobre a leishmaniose tegumentar americana. Cadernos de Saúde Pública, Rio de Janeiro, v.20, n.4, p.935-941, jul./ago, 2004. 